\title{
A Codificação Municipal - Esquema de Londrina e Vitória
}

\author{
A. Delorenzo Neto \\ (Conselheiro da Associação Brasileira \\ dos Municípios)
}

E

M 1950 elaboramos, depois de demorado exame da legislação local, o Código Municipal de Guaranésia. Tínhamos em vista regulamentar num texto único tôdas as relações jurídicas do Município; contudo, apesar de ncssos esforços, êsse Código não disciplinava as relações jurídicas de natureza especial, que, por dificuldade de método, seriam objeto de leis especiais.

Se é verdade, por um lado, que o Código Municipal de Guaranésia deixa de ser um simples Cćdigo de Posturas, para se tornar a disciplina de relações jurídicas numa esfera de ação mais vasta da competência do Município - por outro, podemos afirmar que o prosseguimento dêsses estudos e a reforma da legislação em outros municípios, nos proporcionou um aperfeiçoamento na técnica, o que permitiu, sem dúvida, a unificação completa da matéria, de que é exemplo o Código Municipal de Ourinhos, (1) de 1952, superior, neste sentido, aos trabalhos anteriores. Depois de Ourinhos, ainda avançamcs um passo com a Codificação de Londrina, para atingir maior precisão científica no Código Municipal de Vitória, para o qual fizemos rigorosa reclassificação das matérias. Êsse importante trabalho - a primeira codificação de Capital brasileira - teve assim as suas normas sistematizadas de acôrdo com a sua complexidade crescente e generalidade decrescente.

O esquema do Código de Vitória demonstra a possibilidade da Codificação integral das relações jurídicas do município. Aprovado pela Câmara Municipal, transformou-se na Lei n. ${ }^{\circ} 351$, de 24 de abril de 1954.

(1) Ver os esquemas das Codificações de Guaranésia e Ourinhos na Revista do Serviço Público, Rio, abril de 1953. 
A fim de possibilitar a comparação aos interessados damos aqui o esquema respectivo de ambas as codificações:

\section{ESQUEMA DO CÓDIGO MUNICIPAL DE LONDRINA (PARANÁ)}

MUNICIPIO DE LONDRINA

CÓDIGO MUNICIPAL

Parte Geral

DISPOSIÇÕES PRELIMINARES

LIVRO I

Da Aplicação do Direito Municipal

Tí́tulo ÚNICO

Das Posturas em Geral

Capítulo

Capítulo

Capítulo

Capítulo

Capítulo

Capítulo

Capitulo

Capítulo

Capítulo

Capítulo

Capítulo
I - Da competência.

II - Das infrações e das penas.

III - Dos autos de infração.

IV - Do processó de execução.

\section{LIVRO II}

Do Poder de Polícia

Tírulo I

Da Polícia Sanitária

I - Da higiene das vias públicas.

II - Da higiene das habitações.

III - Da higiene da alimentação.

IV - Disposições gerais.

Tírulo II

Da Polícia de Ordem Pública

I - Dos costumes, da tranquiilidade dos habitantes e dos divertimentos públicos.

II - Do trânsito público, das medidas referentes aos animais e à extinção dos insetos nocivos.

III - Do funcicnamento do comércio e da indústria . 


\section{Parte Especial \\ LIVRO I}

Do Poder Regulamentar Tí́tuLO I

Capítulo

Seção

Seção

Seção

Seção

Seção

Capítulo

Capítulo

Capítulo

Capítulo

Capítulo

Capítulo

Seção

Seção

Seção

Seção

Capítulo

Capítulo

Capítulo

Capítulo

Capítulo

Capítulo

Capítulo
Das Medidas de Urbanismo, Obras e Seǵurança Pública

I - Das condições mínimas.

I - Das normas gerais.

II - Do alinhamento e nivelamento para construção.

III - Do loteamento, arruamento e zoneamento.

IV - Do saneamento rural.

$\mathrm{V}$ - Das penalidades.

II - Das vias e logradouros públicos.

III - Dos tapumes e fechos divisórios.

IV - Do empachamento.

$\mathrm{V}$ - Da numeração de prédios.

VI - Das estradas e caminhos públicos.

VII - Dos cemitérios públicos.

I - Definições.

II - Disposições gerais.

III - Das inumações.

IV - Das construções.

Tírulo II

Das Medidas de Segurança Pública

I - Dos inflamáveis e explosivos.

II - Das queimadas.

TítuLo III

Do Serviço de Abastecimento de Carne Verde

I - Da localização, instalação e funcionamento dos matadcuros.

II - Da matança e inspeção sanitária.

III - Disposições gerais.

IV - Dos açougues e do abastecimento de carne verde.

$\mathrm{V}$ - Das infrações e das penas.

\section{LIVRO II}

Dos Bens

TíruLO ÚNICO

Das Classes de Bens

Capítulo

Capitulo
I - Dos bens móveis e imóveis.

II - Da venda de terrenos do patrimônio municipal. 
Seção

Seção

Seção

Capítulo

Capítulo

Seção

Seção

Seção

Seção

Seção

Seção

Seção

Seção

Seção

Seção

Capítulo

Seção

Seção

Seção

Seção

Seção

Capítulø

Capítulo

Seção

Seção

Seção

Seção

Seção

Seção

Seção

Seção

Seção

Seção
I - Da venda em geral.

II - Da hasta pública para a venda.

III - Dos lotes edificados.

\section{LIVRO III}

- Da Administração Municipal

\section{TítuLo I}

Da Organização dos Serviços

$$
\text { I - Das normas gerais. }
$$

II - Das atribuições.

I - Do Prefeito.

II - Dos Sub-Prefeitos.

III - Das atribuições gerais de chefia.

IV - Do Gabinete do Prefeito e Secretaria.

V - De Departamento da Fazenda.

VI - Do Departamento de Fiscalização.

VII - Do Departamento de Patrimônio.

VIII - Do Departamento de Obras e Planejamento.

IX - Do Departamento de Educação Pública e Assistência Social.

X - Do Departamento Jurídico.

III - Disposições especiais.

I - Do funcionamento das feiras-livres.

II - Da utilização do estádio municipal.

III - Da organização e funcionamento da estação rodoviária.

IV - Da utilização dos veículos da Prefeitura.

$\mathrm{V}$ - Dos serviças de utilidade pública.

Título II

Dos Funcionários Municipais

I - Disposições prévias.

II - Do provimento e vacância dos cargos públicos municipais:

I - Do provimento.

II - Das nomeações.

III - Dos concursos.

IV - Da posse.

$\mathrm{V}$ - Da fiança.

VI - Do exercício.

VII - Da transferência.

VIII - Da readaptaçãc, remoção e permuta.

IX - Da reintegração.

$\mathrm{X}$ - Da readmissão. 


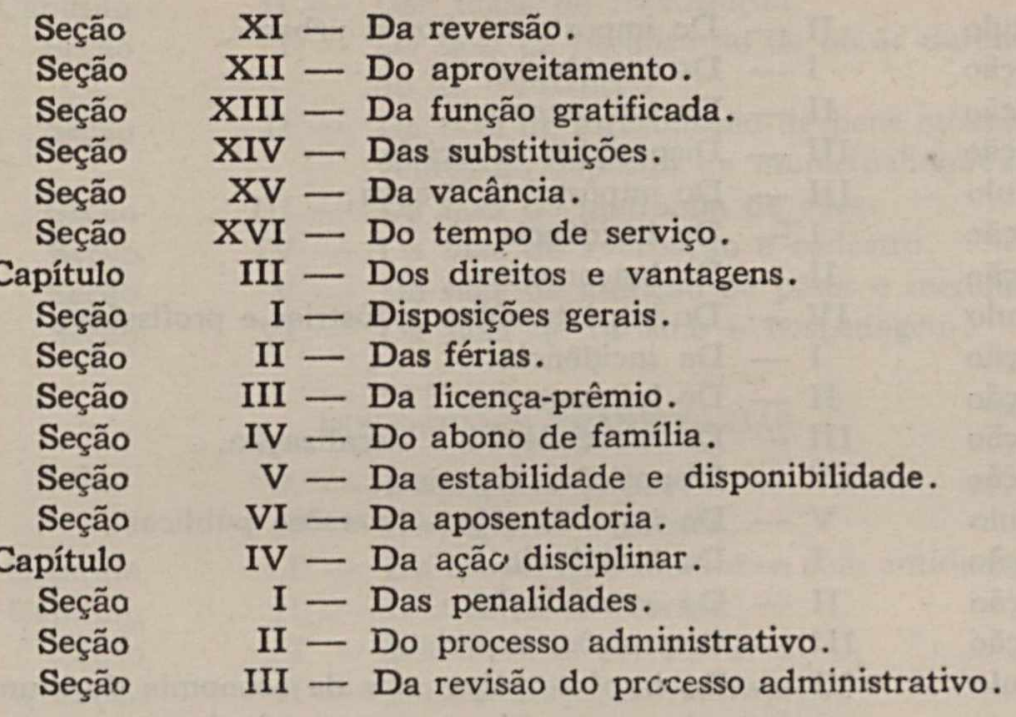

\section{LIVRO VI}

\section{Do Regime Tributário}

Tírulo I

Das Tributações Municipais do Ponto de Vista Jurídico

Capítulo
Capitulo
Capítulo
Capítulo
Seção
Seção
Capítulo
Capítulo
Capítulo 

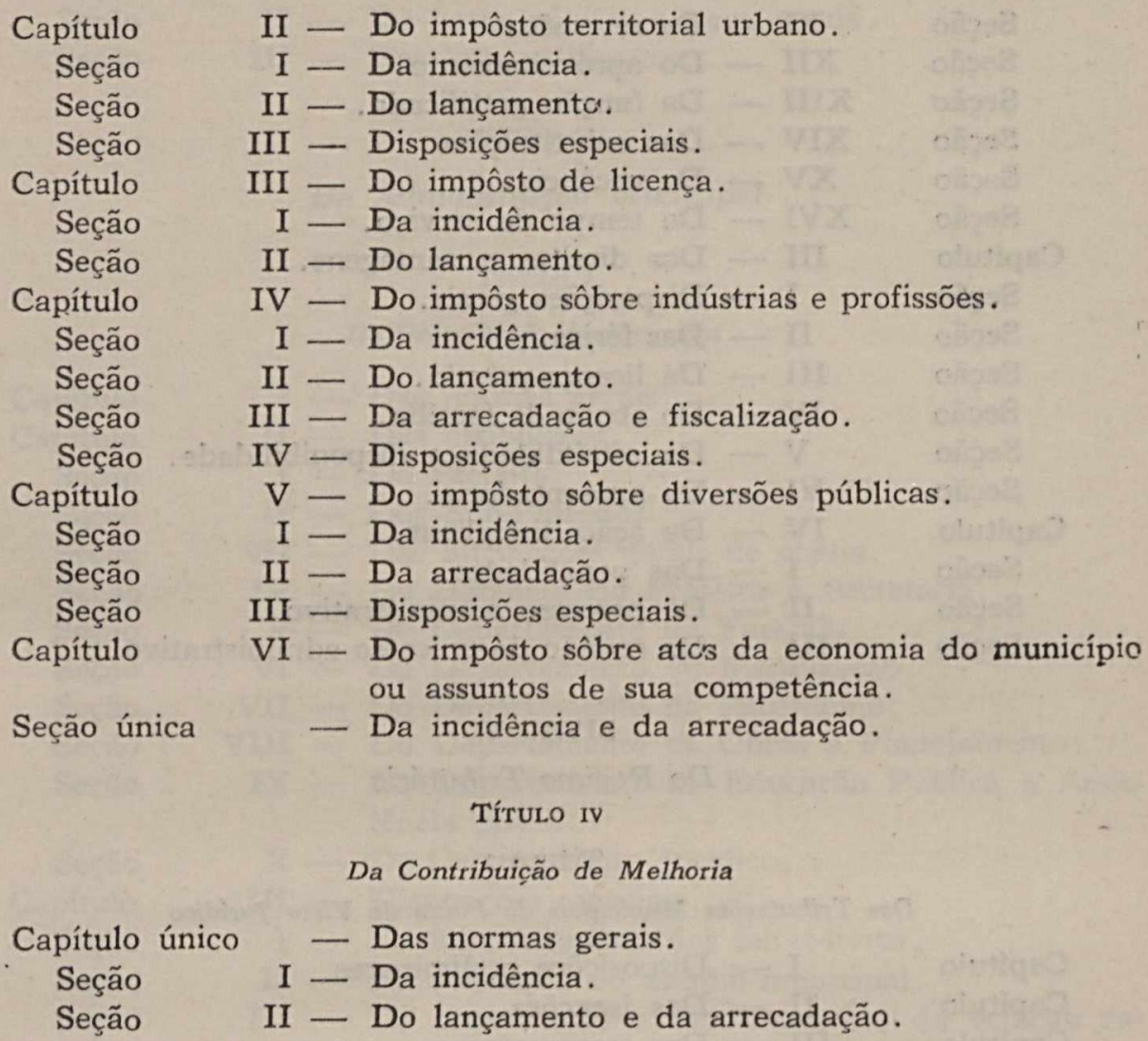

\section{Título $\mathrm{v}$ \\ Das Taxas}

\begin{tabular}{|c|c|c|}
\hline Capítulo & I - & Das taxas de serviços urbanos e rurais. \\
\hline Seção & $\mathrm{I}-$ & Da taxa de água. \\
\hline Seção & II - & Da taxa de esgotos domiciliários. \\
\hline Seção & III - & Da taxa de limpeza das vias públicas. \\
\hline Seção & IV - & Da taxa sôbre o serviço do matadouro. \\
\hline Seção & $\mathrm{V}-$ & Da taxa sôbre o serviço de cemitérios. \\
\hline Seção & $\mathrm{VI}-$ & Da taxa de emplacamento de veículos. \\
\hline Seção & VII & Da taxa de extinção de insetos nocivos. \\
\hline Seçãc & VIII & $\begin{array}{l}\text { Da taxa de nivelamento e alinhamento para cons- } \\
\text { trução. }\end{array}$ \\
\hline Seção & $\mathrm{IX}-$ & Da taxa de numeração de prédios. \\
\hline Seção & $\mathrm{X}-$ & Da taxa de mercado. \\
\hline Seção & $\mathrm{XI}-$ & Da taxa de conservação de calçamento e de guias. \\
\hline Seção & $\mathrm{XII}-$ & $\mathrm{Da}$ taxa de iluminação pública. \\
\hline Seção & XIII - & $\begin{array}{l}\text { Da taxa de conservação e manutenção da esta- } \\
\text { ção rodoviária. }\end{array}$ \\
\hline Seção & XIV & Da taxa de conservação de estradas de rodagem. \\
\hline
\end{tabular}




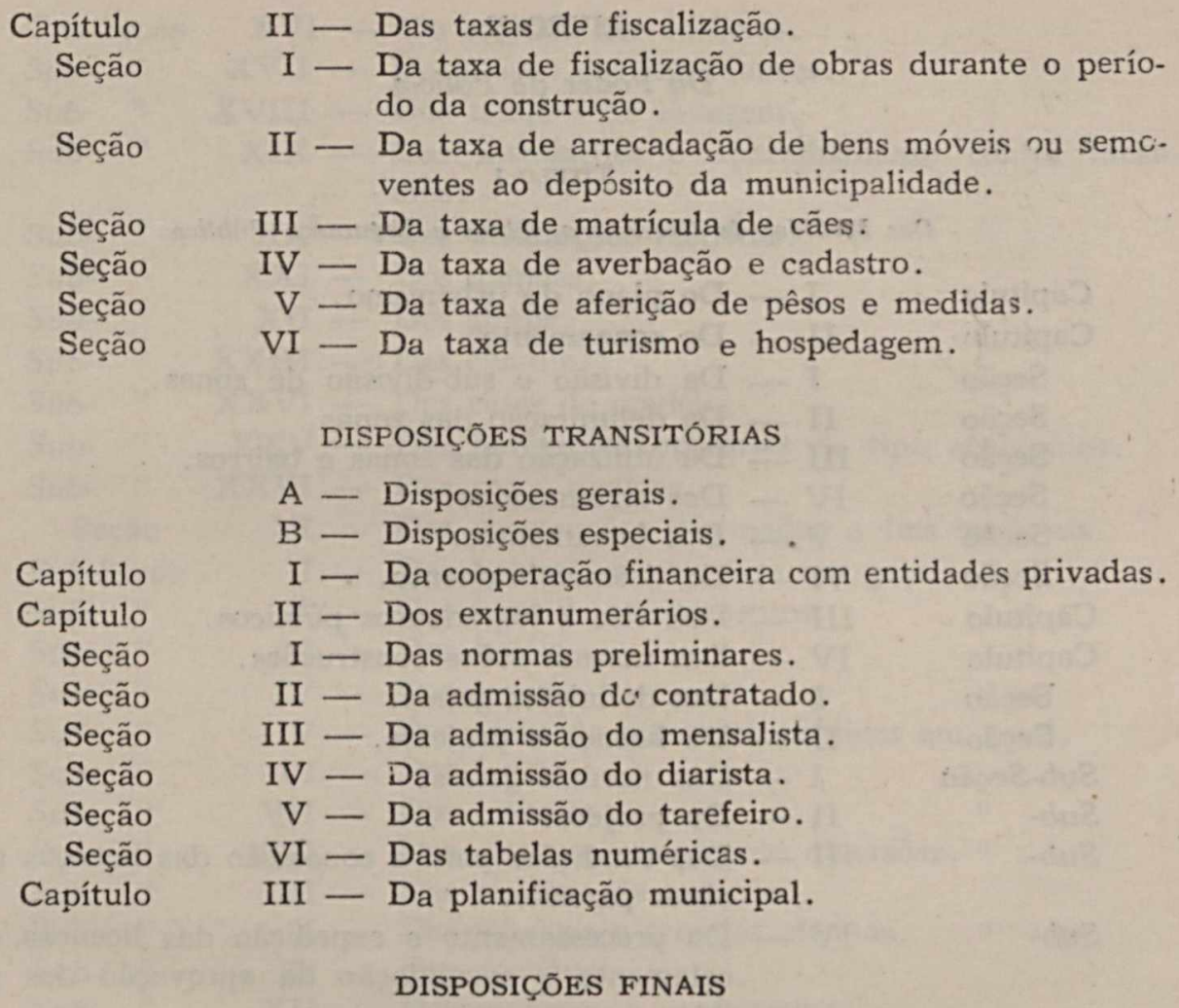

\title{
ESQUEMA DO CÓDIGO MUNICIPAL DE VITÓRIA (ESPÍRITO SANTO)
}

\author{
MUNICÍPIO DE VITÓRIA \\ CÓDIGO MUNICIPAL \\ Parte Geral \\ DISPOSIÇÕES PRELIMINARES
}

\section{LIVRO I}

Da Aplicação do Direito Municipal

\author{
Título Unico \\ Das Posturas em Geral
}

Capítulo

I - Da competência.

Capítulo

II - Das infrações e das penas.

Capítulo

III - Dos autos de infração.

Capítulo

IV - Do processo de execução. 


\section{LIVRO II}

\section{Do Poder de Polícia}

TítuLo $\mathrm{I}$

Das Medidas de Urbanismo, Obras e Segurança Pública

Capítulo
Capítulo
Seção
Seção
Seção
Seção
Seção
Seção
Capítulo
Capítulo
Seção
Seção
Sub-Seção
Sub- "
Sub- "
Sub- "

Seção Sub-Seção

Sub- "

Seção

\section{Seção}

Sub-Seção

Sub-

Sub- "

Sub- "

Sub- "

Sub- "

Sub- "

Sub- "

Sub- "

Sub- "

Sub- "

Sub- "

Sub- "

Sub- "

Sub- "
I - Do plano de urbanismo.

II - Do zoneamento.

I - Da divisão e sub-divisão de zonas.

II - Da delimitação das zonas.

III - Da utilização das zonas e bairros.

IV - Dos arruamentos.

V - Dos loteamentos.

VI - Do desmembramento.

III - Das vias e logradouros públicos.

IV - Das ncrmas sôbre construções.

I - Das definições gerais.

II - Da licença e projetos.

I - Das normas gerais.

II - Do projeto.

III - Das condições para a concessão das licenças para obras parciais.

IV - Do processamento e expedição das licenças cancelamento e revalidação da aprovação dos projetcs.

III - Das obrigações para a execução de obras.

I - Do destino do alvará aprovado - exame de concreto - conclusão de obras.

II - Das obras paralizadas - demolições.

IV - Dos profissionais habilitados a projetar, calcular e construir.

$\mathrm{V}$ - Das condições gerais das construções.

I - Do alinhamento e soleira.

II - Da edificação dos lotes.

III - Do fechamento e conservação de terrenos.

IV - Da localização do prédio e da área ocupada.

$\mathrm{V}$ - Dos pavimentos e altura dos edifícios.

VI - Dos materiais de construção.

VII - Das fundações.

VIII - Do revestimento do solo.

IX - Dos pisos.

$\mathrm{X}$ - Das paredes.

$\mathrm{XI}$ - Das escadas.

XII - Da cobertura.

XIII - Das áreas e reentrâncias.

$\mathrm{XIV}$ - Da iluminação e ventilação

$\mathrm{XV}$ - Dos compartimentos. 


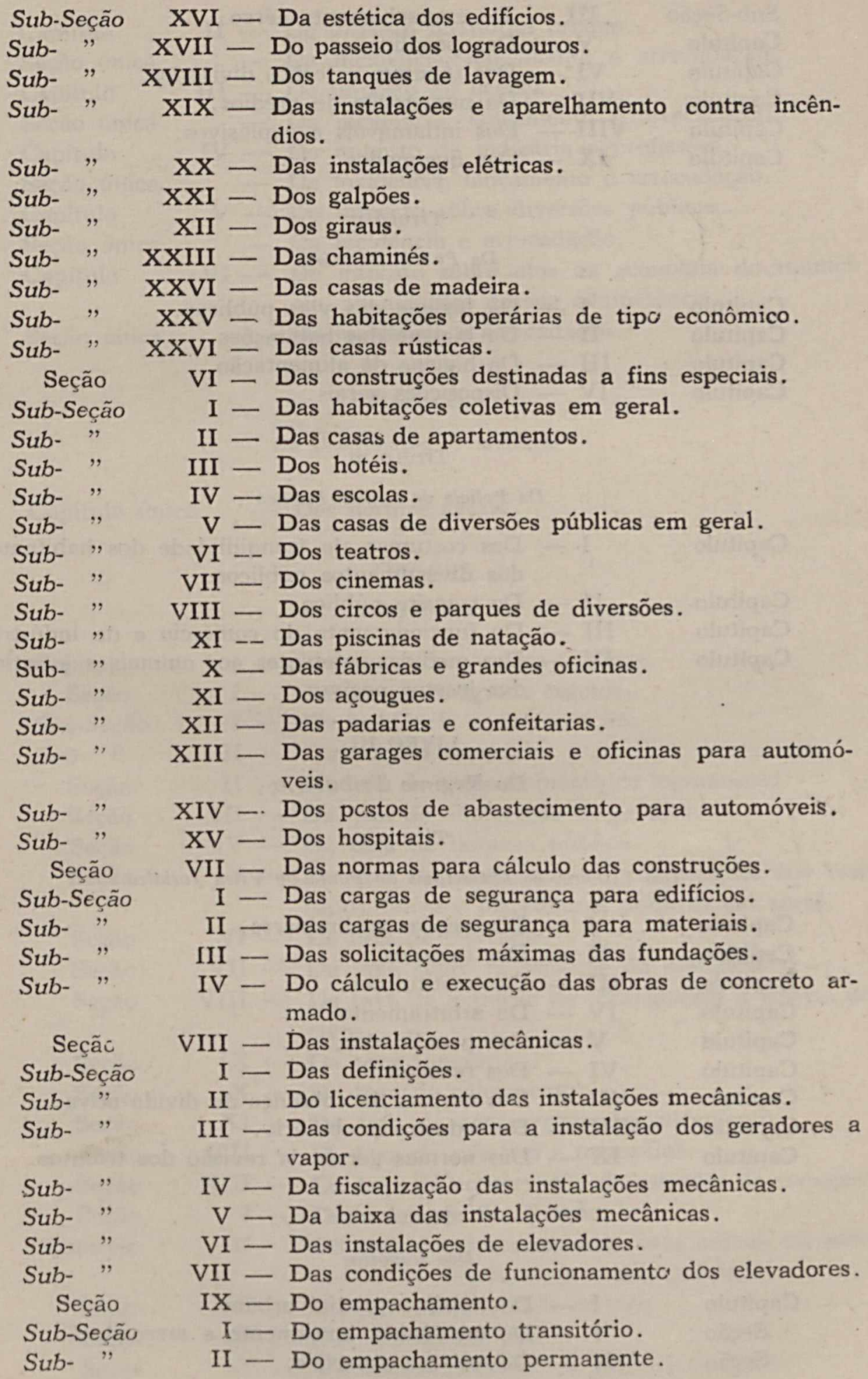


Sub-Seção III - Do empachamento aéreo.

Capítulo $\quad \mathrm{V}-$ Das penalidades.

Capítulo VI - Dos tapumes e fechos divisórios.

Capítulo VII — Da numeração de prédios.

Capítulo VIII - Dos inflamáveis e explosivess.

Capítulo

IX - Das queimadas.

Capítulo $\quad$ I $-\mathrm{Da}$ higiene das vias públicas.

Capítulo II - Da higiene das habitaŗões.

Capítulo III - Da higiene da alimentação.

Capitulo IV - Disposições gerais.

Tí́tuLO III

Da Polícia de Ordem Pública

Capítulo I - Dos costumes, da tranqüilidade dos habitantes e dos divertimentos públicos.

Capítulo II - Do trânsito público.

Capítulo III - Do funcionarnento do comércio e da indústria.-

Capítulo IV - Das medidas referentes aos animais e à extinçãc dos insetos nocivos.

\section{LIVRO III}

Do Regime Tributário

Tí́tuLo I

Das Tributações Municipais do Ponto de Vista Jurídico

Capítulo

Capitulo

Capitulo

Capítulo

Capítulo

Capítulo

Capítulo

Capítulo

Capítulo
I - Disposições preliminares.

II - Das isenções.

III - Das restituições.

IV - Do arbitramento.

$\mathrm{V}$ - Das penalidades.

VI - Dos recursos.

VII - Das normas da cobrança da dívida ativa.

VIII - Do cadastro imobiliáric.

IX - Das normas gerais da revisão dos tributos.

Tí́tulo II

Dos Impostos

Capítulo

Seção

Seção

I - Do impôsto predial urbano.

I - Da incidência, lançamento e arrecadação.

II - Disposições especiais. 
Capítulo

Seção única

Capítulo

Seção única

Capítulo

Seção única

Capítulo

Seção única

Capítulo

Seção única
II - Do impôsto territorial urbano.

- Da incidência, lançamento e arrecadação.

III - Do impôsto de licença.

- Da incidência, lançamento e arrecadação.

IV - Do impôsto de indústria e profissões.

- Da incidência, lançamento e arrecadação.

$\mathrm{V}$ - Do impôsto sôbre diversões públicas.

- Da incidência e arrecadação.

VI - Do impôsto sôbre atos da economia do município, ou assuntos de sua competência.

- Da incidência c arrecadação.

\section{Tírulo III}

Da Contribuição de Melhoria

Capítulo único - Das normas gerais.

Título IV

Das Taxas 


\section{TíruLo v \\ Disposições Gerais \\ Parte Especial \\ LIVRO I}

Dos Funcionários Municipais

Tí́tuLO ÚNICO

Das Normas Gerais

LIVRO II

Disposições Regulamentares Especiais

Tírulo I

Dos Serviços de Utilidade Pública

Título II

Do Abastecimento de Águas, Esgotos Sanitários e Águas Plaviais

Capítulo

Capítulo

Capitulo

Capítulo

Seção

Seção

Capítulo

Capitulo

I - Disposições preliminares.

II - Da distribuição de água e hidrômetros.

III - Das captações de água para uso particular.

IV - Dos esgotos sanitários e águas pluviais.

I - Do esgotamento e rêdes domiciliárias.

II - Das instalações internas.

$\mathrm{V}$ - Das águas pluviais internas.

IV - Das casas e bombeiros instaladores.

Tírulo III

Do Abastecimento de Carne Verde

Capítulo

Capítulo

Capítulo

I - Da matança e inspeção sanitária.

II - Do abastecimento de carne verde.

III - Disposições gerais.

\section{Título $\mathrm{IV}$}

Dos Mercados

Capítulo

Capítulo

Capítulo

I - Da utilização.

II - Da locação de cômodos.

III - Do comércio em áreas abertas.

Título $\mathrm{v}$

Das Feiras 
TíruLO VI

Da Utilização dos Veículos da Prefeitura

Tí́tulo vII

Do Funcionamento dos Alto-Falantes

TítuLo vIII

Da Cooperação Financeira com as Entidades Privadas

Tí́tuLo IX

Dos Cemitérios Públicos

Capítulo

Capítulo

Capítulo

I - Das inumações.

II - Das construções.

III - Disposições gerais.

\section{DISPOSIÇÕES TRANSITÓRIAS}

Capítulo

Capítulo

I - Disposições preliminares.

II - Da planificação municipal.

Seção

I - Das condições mínimas.

Seção

II - Dos recursos financeiros.

\section{DISPOSIÇÕES FINAIS}

